ORIGINAL ARTICLE

\title{
Neonatal respiratory morbidity at term and the risk of childhood asthma
}

\author{
G C S Smith, A M Wood, I R White, J P Pell, A D Cameron, R Dobbie
}

Arch Dis Child 2004;89:956-960. doi: 10.1136/adc.2003.045971

See end of article for authors' affiliations .....................

Correspondence to: Professor G C S Smith, Department of Obstetrics and Gynaecology, Cambridge University, Box 223, The Rosie Hospital, Robinson Way

Cambridge, CB2 2QQ

UK; gcss2@cam.ac.uk

Received 26February 2004

Accepted for publication

9 March 2004
Objective: To determine whether neonatal respiratory morbidity at term is associated with an increased risk of later asthma and whether this may explain previously described associations between caesarean delivery and asthma.

Design: Retrospective cohort study using Scottish Morbidity Record (SMR) data of maternity (SMR02), neonatal (SMR11), and acute hospital (SMRO1) discharges.

Setting: Scotland.

Participants: All singleton births at term between 1992-1995 in 23 Scottish maternity hospitals.

Main outcome measures: Hospital admission with a diagnosis of asthma in the principal position between 1992 and 2000.

Results: Children who had a diagnosis of transient tachypnoea of the newborn or respiratory distress syndrome were at increased risk of being admitted to hospital with a diagnosis of asthma (hazard ratio (HR) $1.7,95 \%$ confidence interval $(95 \% \mathrm{Cl}) 1.4$ to $2.2, \mathrm{p}<0.001)$. This association was observed both among children delivered vaginally (HR 1.5, 95\% $\mathrm{Cl} 1.1$ to $2.0, \mathrm{p}=0.007$ ) and among those delivered by caesarean section (HR 2.2, 95\% Cl 1.6 to 3.0, $\mathrm{p}<0.001$ ). In the absence of neonatal respiratory morbidity, delivery by caesarean section was weakly associated with the risk of asthma in childhood (HR $1.1,95 \% \mathrm{Cl} 1.0$ to 1.2, $\mathrm{p}=0.004)$. The strengths of the associations were similar whether the caesarean delivery was planned or emergency and were not significantly altered by adjustment for maternal, obstetric, and other neonatal characteristics.

Conclusions: Neonatal respiratory morbidity at term is associated with an increased risk of asthma in childhood which may explain previously described associations between caesarean delivery and later asthma.
$\mathrm{R}$ ecent studies have demonstrated that children delivered by caesarean section have an increased risk of hospital admission for asthma in childhood. ${ }^{12}$ It has been hypothesised that this may be explained by effects of mode of delivery on the gut and susceptibility to atopy. However, caesarean delivery is a well recognised cause of neonatal respiratory morbidity at term, specifically, transient tachypnoea of the newborn and respiratory distress syndrome. ${ }^{34} \mathrm{~A}$ number of previous studies have demonstrated that neonatal respiratory morbidity secondary to preterm delivery is associated with an increased risk of later asthma. ${ }^{5-8}$ However, there are no studies, to our knowledge, which have examined the risk of later asthma in relation to neonatal respiratory morbidity confined to term births. The aims of the present study were to determine whether neonatal respiratory morbidity at term was associated with an increased risk of later asthma and to determine whether any observed association varied in relation to mode of delivery.

\section{METHODS}

\section{Patient selection}

The Scottish Morbidity Record 2 (SMR02) collects information on clinical and demographic characteristics and outcomes for all women discharged from Scottish maternity hospitals. The register is subjected to regular quality assurance checks and has been greater than $99 \%$ complete since the late 1970s. ${ }^{9}$ Data were extracted on all singleton liveborn infants delivered between 37 and 43 weeks gestation inclusive in Scotland between 1992 and 1995 (inclusive). SMR02 records were linked to the SMR1l (1992-1995) database, which collects discharge data on all neonates delivered in Scottish hospitals, and to the SMR01, which collects discharge data on all acute hospital admissions in Scotland. SMR01 admissions were analysed from 1st January 1992 to 31 st December 2000, providing between 5 and 9 years of follow up on the cohort. All linkages were performed using a probability based matching approach which has been described in detail elsewhere..$^{10}$ Therefore, the final linked file contained demographic, obstetric, and neonatal characteristics and dates of hospital admission of the child. Ethical approval for the linkage was obtained from the Privacy Advisory Committee of the Information and Statistics Division of the National Health Service in Scotland. The data sources employed are given in table 1 .

\section{Exclusion criteria}

Multiple pregnancies, stillbirths, births outside the range 3743 weeks gestation, births in hospitals that performed less than 100 planned caesarean deliveries over the study period, and vaginal breech births were all excluded. Records were also excluded where there were missing values for any of the covariates.

\section{Obstetric definitions}

Gestational age at birth was defined as completed weeks of gestation on the basis of the estimated date of delivery in each woman's clinical record. Gestational age has been confirmed by ultrasound scan in the first half of pregnancy in more than $95 \%$ of pregnancies in the UK since the early

Abbreviations: $H R$, hazard ratio; ICD, International Classification of Disease; IQR, inter-quartile range; RDS, respiratory distress syndrome; SMR, Scottish Morbidity Record; TTN, transient tachypnoea of the newborn 


\begin{tabular}{llll} 
Table 1 & Data sources & & \\
\hline Database & Data type & Years* & Data extracted \\
\hline SMR02 & Maternal hospital discharge & $1992-1995$ & Obstetric, maternal (including ICD9 diagnoses), and neonatal characteristics \\
SMR11 & Neonatal discharge & $1992-1995$ & Neonatal diagnoses (ICD9) \\
GRO & Death certificate & $1992-2000$ & Deaths \\
SMRO1 & General and paediatric hospital discharge & $1992-2000$ & Hospital discharges with diagnosis of asthma (ICD9 and ICDI0) \\
\hline
\end{tabular}

GRO, General Registrar's Office; ICD, International Classification of Disease; SMR, Scottish Morbidity Record.

${ }^{*}$ All dates are inclusive.

$1990 \mathrm{~s}^{11}$ and standard national criteria exist for the estimation of date of delivery using menstrual and ultrasound data. ${ }^{12}$ Smoking was defined as the smoking status of the woman at the time of first attendance for antenatal care. Maternal age was defined as the age of the mother at the time of delivery. Postcode of residence was used to derive Carstairs socioeconomic deprivation categories. ${ }^{13}$ These are based on 1991 Census data on car ownership, unemployment, overcrowding, and social class within postcode sectors of residence which contain, on average, around 1600 residents. Emergency caesarean section was defined as any nonplanned caesarean delivery. Mothers with asthma were diagnosed by ICD 9 diagnostic code 493 in any position.

\section{Paediatric definitions}

Neonatal respiratory morbidity was documented in the SMR1l record using ICD9 diagnostic codes. Neonatal respiratory morbidity was defined as respiratory distress syndrome (769.9) or transient tachypnoea of the newborn (770.6) in any position. Infants who had neither of these diagnoses formed the reference category. Infants with other perinatal respiratory diagnoses were excluded (770.2-770.5 and 770.7-770.9) since these diagnoses were either rare or non-specific and therefore difficult to analyse and interpret. Infants with aspiration documented were also excluded (770.1). Hospital admissions in childhood for asthma were classified by ICD9 or ICD10 codes from the SMR01 registry and admission for asthma was defined as 493 (ICD9) or J45J46 (ICD10) in the principal position. We also obtained data on hospital discharge for a condition which should be independent of mode of delivery in order to detect bias towards hospital admission in relation to mode of delivery due to selective migration. The outcome studied was fracture of an upper limb long bone, defined as 812-813 (ICD9) or S422-S424, S52 (ICD10) in the principal position.

\section{Statistical analyses}

Continuous variables were summarised by the median and inter-quartile range (IQR) and comparisons between groups were performed using the Mann-Whitney U test. Univariate comparisons of categorical data were performed using the $\chi^{2}$ test. The $\mathrm{p}$ values for all hypothesis tests were two sided and statistical significance was assumed at $p<0.05$. The risk of asthma and fractured long bone was assessed using a proportional hazards model of the time to first hospital admission. All categorical covariates were modelled by dummy variables. Birth weight was converted to a z score relative to the mean birth weight for the week of gestation of delivery and sex. The proportional hazards assumption was tested using the test of Grambsch and Therneau. ${ }^{14}$ If the proportional hazards assumption was violated by a covariate, multivariate analysis was stratified by categories of the given factor. Otherwise, all numerical variables (gestational age, maternal age, height, and normalised birth weight) were treated as continuous in the statistical models. Assessment of linearity in the log hazard scale and selection of polynomials was performed using fractional polynomials. ${ }^{15}$ All models employed robust standard errors and the analysis clustered on a maternal identifier to allow for dependence within siblings. The statistical significance of interaction terms was assessed using the Wald test (accounting for clustering) and statistical significance of interactions was assumed at $\mathrm{p}<0.01$. The goodness of fit of models was assessed using the May and Hosmer test. ${ }^{16}$ All statistical analyses were performed using the Stata software package (Stata, TX, USA), version 8.2 .

\section{RESULTS}

There were records for 241846 singleton live births in Scotland over the period 1992-1995. We excluded 27604 (11.4\%) records where the hospital of delivery performed less than 100 planned caesarean deliveries or the gestational age was outside the range 37-43 weeks. Among the remaining 214242 births, there were missing values for maternal height in $16572(7.7 \%)$, for smoking in $21880(10.2 \%)$, for sex in four $(<0.1 \%)$, for deprivation category in $727(0.3 \%)$, for birth weight in $38(<0.1 \%)$, for mode of delivery in 66 $(<0.1 \%)$, for parity in $151(0.1 \%)$, induced labour in 13 $(<0.1 \%)$, and neonatal respiratory diagnosis in $2929(1.4 \%)$. In total 37454 records $(17.5 \%)$ had one or more of these missing values. Of the remaining 176788 records, there was a perinatal respiratory diagnosis other than transient tachypnoea or respiratory distress syndrome in 3050 (1.7\%) and $615(0.3 \%)$ were vaginal breech births. There was overlap between these categories and the final study group was 173319 .

The demographic, obstetric, and neonatal characteristics of the study group are tabulated by neonatal respiratory morbidity (table 2). With the exceptions of deprivation category and whether labour was induced, all the characteristics of the group varied according to neonatal respiratory morbidity. Infants who experienced neonatal respiratory morbidity were at increased risk of hospital admission with a diagnosis of asthma in later childhood (fig 1). A test for interaction between caesarean delivery and neonatal respiratory morbidity demonstrated a trend for a stronger association between neonatal respiratory morbidity among babies delivered by caesarean section: the hazard ratio (HR) for the interaction was 1.4 (95\% confidence interval (CI) 0.9 to 2.2, $\mathrm{p}=0.1)$. Further analysis was performed following separation into those delivered vaginally and those delivered by caesarean section.

The crude number of events, years of follow up, and expected number of admissions are given in table 3. Among those delivered by caesarean section, the association between neonatal respiratory morbidity and later asthma did not significantly differ according to whether the procedure was planned or emergency $(p=0.9)$. The associations were minimally affected by adjusting for maternal, other obstetric, and neonatal characteristics (table 3). There were no significant interactions between mode of delivery or neonatal respiratory morbidity and any of these other factors in the multivariate model. 


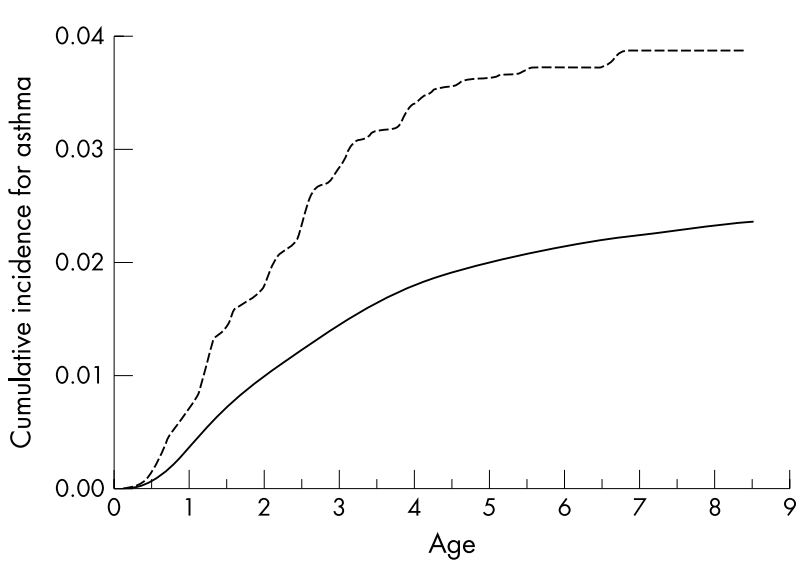

Figure 1 Cumulative incidence of hospital admission for asthma over the first 8-9 years of life for children born at term with neonatal respiratory morbidity (broken line, defined as respiratory distress syndrome or transient tachypnoea of the newborn) and those with no neonatal respiratory morbidity (solid line). Comparison of curves (log rank test): $p<0.001$. HR for neonatal respiratory morbidity $=1.7,95 \%$ Cl 1.4 to 2.2 .

Including the 3050 cases with a non-infective perinatal respiratory diagnosis other than transient tachypnoea or respiratory distress syndrome had virtually no effect on the HRs in table 3. We examined the risk of hospital admission for fractured long bone after 3 months of age to test for bias in hospital admission in relation to mode of delivery or neonatal morbidity, for example due to selective migration. There were 2218 hospital admissions with a fractured upper limb long bone. There was no statistically significant association between admission for long bone fracture and neonatal respiratory morbidity (adjusted HR 0.8, 95\% CI 0.5 to $1.2, \mathrm{p}=0.2$ ).

\section{DISCUSSION}

This is the first study to our knowledge to examine the risk of later asthma among children who experience neonatal respiratory morbidity confined to births at term. The main finding of this paper is that neonates who experience respiratory distress syndrome or transient tachypnoea of the newborn at term are at increased risk of asthma in childhood. The relationship was unaltered by adjusting for hospital of birth, maternal age, height, deprivation category, parity and smoking, induction of labour, week of gestation of delivery, and the child's birth weight, sex, and Apgar score. The association is plausible since previous studies have shown increased risks of later asthma associated with neonatal respiratory morbidity secondary to preterm delivery. ${ }^{5-8}$

It is possible that the association between neonatal respiratory morbidity is explained by some unmeasured confounder. For instance, it has been shown that the offspring of asthmatic women are more likely to experience neonatal respiratory morbidity in neonatal life. ${ }^{17}$ However, we found no effect of adjusting for a maternal diagnosis of asthma. Moreover, caesarean section is a well recognised cause of neonatal respiratory morbidity ${ }^{3}$ and in our own study we estimated that two thirds of neonatal respiratory morbidity in the caesarean delivery group could be attributed to the mode of delivery. If the relationship between neonatal respiratory morbidity and later asthma was due to the effect of an unmeasured confounder, we would have anticipated a weaker association between neonatal respiratory morbidity and asthma in the caesarean delivery group, since most neonatal respiratory morbidity was determined by the mode of delivery. However, the interaction term between neonatal respiratory morbidity and caesarean delivery was 1.4 and had confidence intervals of 0.9 to 2.2. This indicates that the relationship between neonatal respiratory morbidity and later asthma is at least as strong in the caesarean delivery group

Table 2 Demographic, obstetric, and neonatal characteristics of cohort by neonatal respiratory morbidity

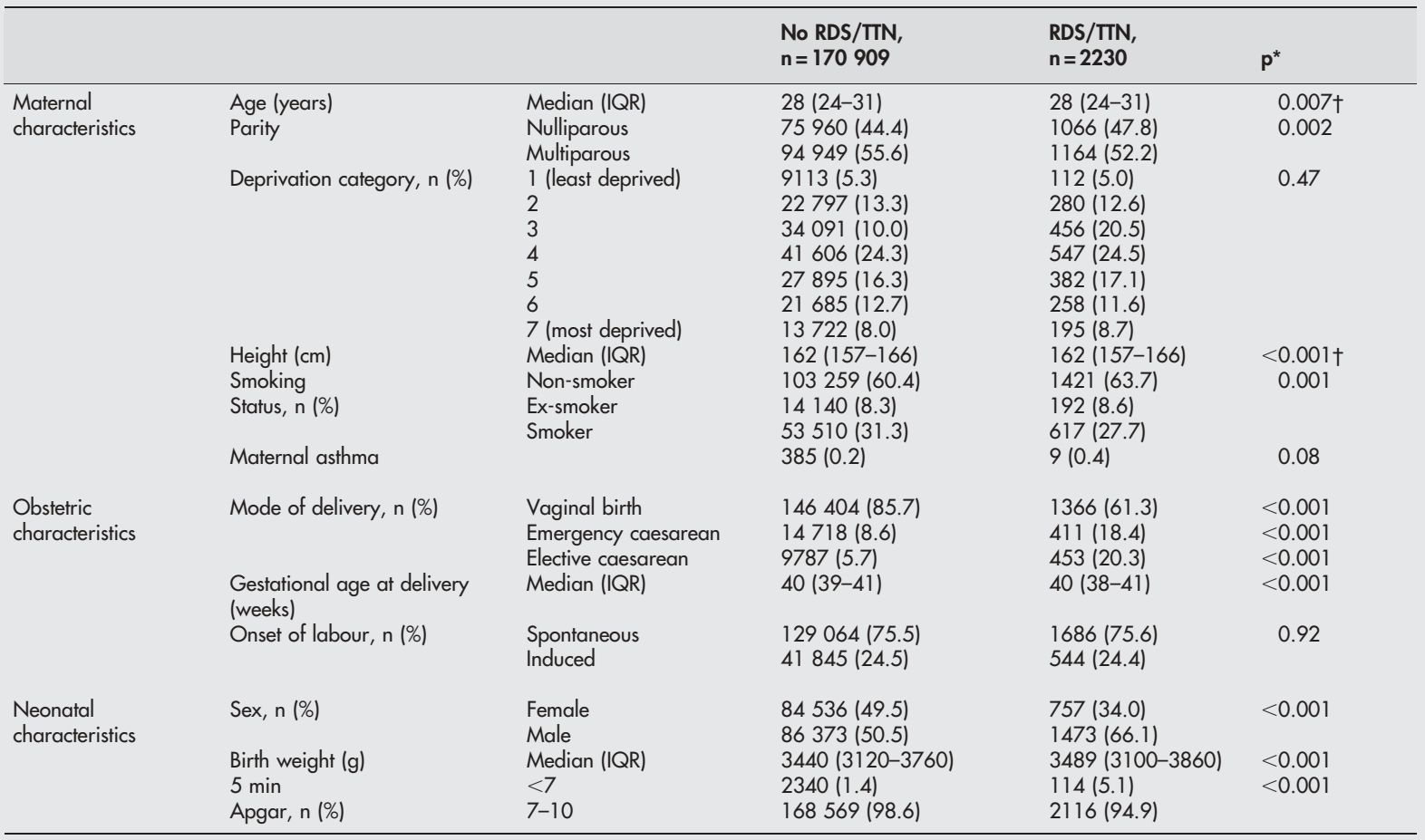

* $\chi^{2}$ test or Mann-Whitney $U$ test, as appropriate.

†Although the medians and IQR do not differ, the groups were different due to less than 1 unit differences in these variables between the two groups. $I Q R$, inter-quartile range; RDS, respiratory distress syndrome; $T N$, transient tachypnoea of the newborn. 
Table 3 Number of events, follow up, and incidence of first hospital admission for asthma in relation to mode of delivery and neonatal respiratory morbidity

\begin{tabular}{|c|c|c|c|c|c|c|c|c|c|}
\hline & $\begin{array}{l}\text { Mode of delivery } \\
\text { and neonatal } \\
\text { characteristics }\end{array}$ & n & $\begin{array}{l}\text { Number of } \\
\text { asthma } \\
\text { admissions }\end{array}$ & $\begin{array}{l}\text { Total years } \\
\text { of follow } \\
\text { up }\end{array}$ & $\begin{array}{l}\text { Expected } \\
\text { asthma } \\
\text { admissions }\end{array}$ & $\begin{array}{l}\text { Crude HR } \\
(95 \% \mathrm{Cl})\end{array}$ & $p$ & $\begin{array}{l}\text { †Adjusted HR } \\
(95 \% \mathrm{Cl})\end{array}$ & $\mathbf{p}$ \\
\hline Vaginal birth & $\begin{array}{l}\text { No TTN/RDS* } \\
\text { With TTN/RDS }\end{array}$ & $\begin{array}{l}146404 \\
1366\end{array}$ & $\begin{array}{r}3171 \\
44\end{array}$ & $\begin{array}{l}1002961 \\
9218\end{array}$ & $\begin{array}{r}3264 \\
30\end{array}$ & $\begin{array}{l}(1.0) \\
1.5(1.1 \text { to } 2.0)\end{array}$ & 0.007 & $\begin{array}{l}(1.0) \\
1.4(1.0 \text { to } 1.8)\end{array}$ & 0.04 \\
\hline $\begin{array}{l}\text { All caesarean } \\
\text { sections }\end{array}$ & $\begin{array}{l}\text { No TTN/RDS } \\
\text { With TTN/RDS }\end{array}$ & $\begin{array}{l}24505 \\
864\end{array}$ & $\begin{array}{r}601 \\
40\end{array}$ & $\begin{array}{l}166397 \\
5767\end{array}$ & $\begin{array}{r}544 \\
19\end{array}$ & $\begin{array}{l}1.1(1.0 \text { to } 1.2) \\
2.2(1.6 \text { to } 3.0)\end{array}$ & $\begin{array}{r}0.004 \\
<0.001\end{array}$ & $\begin{array}{l}1.1(1.0 \text { to } 1.2) \\
2.2(1.6 \text { to } 3.0)\end{array}$ & $\begin{array}{r}0.006 \\
<0.001\end{array}$ \\
\hline $\begin{array}{l}\text { Emergency } \\
\text { caesarean } \\
\text { section }\end{array}$ & $\begin{array}{l}\text { No TTN/RDS* } \\
\text { With TTN/RDS }\end{array}$ & $\begin{array}{l}14718 \\
411\end{array}$ & $\begin{array}{r}357 \\
18\end{array}$ & $\begin{array}{l}99848 \\
2775\end{array}$ & $\begin{array}{r}326 \\
9\end{array}$ & $\begin{array}{l}1.1(1.0 \text { to } 1.3) \\
2.1(1.3 \text { to } 3.3)\end{array}$ & $\begin{array}{l}0.034 \\
0.002\end{array}$ & $\begin{array}{l}1.1(1.0 \text { to } 1.3) \\
2.2(1.4 \text { to } 3.6)\end{array}$ & $\begin{array}{l}0.04 \\
0.001\end{array}$ \\
\hline $\begin{array}{l}\text { Elective } \\
\text { caesarean } \\
\text { section }\end{array}$ & $\begin{array}{l}\text { No TTN/RDS } \\
\text { With TTN/RDS }\end{array}$ & $\begin{array}{l}9787 \\
453\end{array}$ & $\begin{array}{r}244 \\
22\end{array}$ & $\begin{array}{l}66549 \\
2992\end{array}$ & $\begin{array}{r}217 \\
10\end{array}$ & $\begin{array}{l}1.2(1.0 \text { to } 1.3) \\
2.3(1.5 \text { to } 3.5)\end{array}$ & $\begin{array}{r}0.031 \\
<0.001\end{array}$ & $\begin{array}{l}1.1(1.0 \text { to } 1.3) \\
2.2(1.4 \text { to } 3.4)\end{array}$ & $\begin{aligned} & 0.06 \\
< & 0.001\end{aligned}$ \\
\hline
\end{tabular}

*Reference category.

†Hazards were non-proportional for hospital, maternal age, birth weight for gestation, parity, and smoking. Therefore, multivariate analysis was stratified by these variables and adjusted for induction, maternal height, week of gestation, male sex, Apgar, deprivation category, and maternal asthma. Goodness of fit: $p=0.4$. RDS, denotes respiratory distress syndrome; TTN, transient tachypnoea of the newborn.

and, indeed, there was a trend towards a stronger association among women delivered by caesarean section than those delivered vaginally.

Previous studies had demonstrated increased risks of asthma among children delivered by caesarean section. ${ }^{12}$ However, these studies lacked data on neonatal complications and hypothesised that the relationship may be explained by effects of caesarean section on intestinal microbial flora leading to susceptibility to atopic conditions. Both studies described relatively weak associations with odds ratios for asthma among children delivered by caesarean section of 1.2 to 1.4. Our data suggest that the association between caesarean delivery and later asthma may be mediated by neonatal respiratory morbidity. This would explain why the overall association between caesarean birth and asthma is weak since the majority of infants delivered by caesarean section do not experience neonatal respiratory morbidity. Serial population prevalence studies have suggested that rates of wheezing disorders in children are increasing..$^{18}$ Given that this has occurred over a period where caesarean delivery rates have increased, further research is required to determine the possible contribution of increasing rates of caesarean delivery to the increased prevalence of childhood wheezing.

The strengths of the present study are the scale and the fact that exposure data were collected prospectively and independently of outcome data. As with other large scale registry based studies, however, the amount of information on each individual case was relatively limited. We lacked data on breast feeding. However, recent large scale longitudinal studies have cast doubt on the protective effect of breastfeeding on asthma risk ${ }^{19}$ and studies which have shown an increased risk of asthma among bottle fed infants describe a relative risk of asthma in the region of $1.4^{20}$ which could clearly not cause a relative risk of 2.2 by confounding. It is likely that the indication for caesarean section may lead to systematic differences in treatment in neonatal life compared with infants delivered vaginally. It is theoretically possible, for example, that the association with later asthma might be explained by a confounding effect of early antibiotic treatment. However, the incidence of suspected or proven sepsis among infants delivered by emergency caesarean section is $14 \%$ compared with $2 \%$ among infants delivered by planned caesarean section. ${ }^{21}$ Since we saw virtually identical relationships between planned and emergency caesarean section and later asthma, the association is unlikely to be explained by confounding effects of either the indication for caesarean delivery or post-natal treatment of the child.

The outcome measured was hospital admission for asthma which will necessarily involve the severe end of the disease spectrum. Further studies should address the relationship between neonatal respiratory morbidity and asthma managed in the community. The follow up period in our study was limited to childhood. Recent studies have reported a greater than threefold risk of asthma in adulthood and caesarean delivery. ${ }^{22}$ The possible role of neonatal respiratory morbidity in the aetiology of adult asthma remains to be determined.

\section{CONTRIBUTORS}

GS had the original idea and formulated the hypothesis. RD performed the record linkage and prepared the data for analysis. AW and IW performed the statistical analysis. GS, JP, AW, and IW interpreted the results. GS drafted the manuscript and all authors edited and approved the final version.

\section{ACKNOWLEDGEMENTS}

This work was funded by a Yorkhill NHS Trust research support grant.

\section{Authors' affiliations}

G C S Smith, Department of Obstetrics and Gynaecology, Cambridge University, Cambridge, UK

A M Wood, I R White, Medical Research Council Biostatistics Unit, Institute of Public Health, Cambridge, UK

J P Pell, Department of Public Health, Greater Glasgow NHS Board, Glasgow, UK

A D Cameron, Department of Fetal Medicine, The Queen Mother's Hospital, Glasgow, G3 8SH, UK

R Dobbie, Information and Statistics Division, Common Services Agency, Edinburgh, UK

Conflict of interest: none declared.

\section{REFERENCES}

1 Xu B, Pekkanen J, Jarvelin MR. Obstetric complications and asthma in childhood. J Asthma 2000;37:589-94.

2 Kero J, Gissler M, Gronlund MM, et al. Mode of delivery and asthma - is there a connection? Pediatr Res 2002;52:6-11.

3 Dani C, Reali MF, Bertini G, et al. Italian Group of Neonatal Pneumology. Risk factors for the development of respiratory distress syndrome and transient tachypnoea in newborn infants. Eur Respir J 1999;14:155-9.

4 Morrison JJ, Rennie JM, Milton PJ. Neonatal respiratory morbidity and mode of delivery at term: influence of timing of elective caesarean section. $\mathrm{Br} J \mathrm{Obstet}$ Gynaecol 1995;102:101-6. 
5 Bertrand JM, Riley SP, Popkin J, et al. The long-term pulmonary sequelae of prematurity: the role of familial airway hyperreactivity and the respiratory distress syndrome. N Engl J Med 1985;312:742-5.

6 Pelkonen AS, Hakulinen AL, Turpeinen M. Bronchial lability and responsiveness in school children born very preterm. Am J Respir Crit Care Med 1997; 156:1178-84.

7 Evans M, Palta M, Sadek M, et al. Associations between family history of asthma, bronchopulmonary dysplasia, and childhood asthma in very low birth weight children. Am J Epidemiol 1998;148:460-6.

$8 \mathrm{Ng} \mathrm{DK}$, Lau WY, Lee SL. Pulmonary sequelae in long-term survivors of bronchopulmonary dysplasia. Pediatr Int 2000;42:603-7.

9 Cole SK. Scottish maternity and neonatal records. In: Chalmers I, Mcllwaine GM, eds. Perinatal audit and surveillance. London: Royal College of Obstetricians and Gynaecologists, 1980:39-51.

10 Kendrick S, Clarke J. The Scottish Record Linkage System. Health Bull (Edinb) 1993;51:72-9.

11 Campbell S, Soothill PW. Detection and management of intrauterine growth retardation: a British approach. In: Chervenak FA, Isaacson GC, Campbell S, eds. Ultrasound in obstetrics and gynaecology. Vol 2. Boston: Little Brown, 1993: 1432-5.

12 Evans E, Farrant $P$, Gowland $M$, et al. Clinical applications of ultrasonic fetal measurements. London: British Medical Ultrasound Society/British Institute of Radiology, 1990.

13 McLoone P, Boddy FA. Deprivation and mortality in Scotland, 1981 and 1991. BMJ 1994;309: 1465-70.
14 Grambsch PM, Therneau TM. Proportional hazards tests and diagnostics based on weighted residuals. Biometrika 1994;81:515-26.

15 Royston P, Altman DG. Regression using fractional polynomials of continuous covariates: parsimonious parametric modeling. Appl Stat 1994:43:429-67.

16 May S, Hosmer DW. A simplified method of calculating an overall goodnessof-fit test for the Cox proportional hazards model. Lifetime Data Anal 1998:4:245-55.

17 Schatz M, Zeiger RS, Hoffman CP, et al. Increased transient tachypnea of the newborn in infants of asthmatic mothers. Am J Dis Child 1991;145:156-8.

18 Kuehni CE, Davis A, Brooke AM, et al. Are all wheezing disorders in very young (preschool) children increasing in prevalence? Lancet 2001;357:1821-5

19 Sears MR, Greene JM, Willan AR, et al. Long-term relation between breastfeeding and development of atopy and asthma in children and young adults: a longitudinal study. Lancet 2002;360:901-7.

20 Gdalevich M. Mimouni D. Mimouni M. Breast-feeding and the risk of bronchial asthma in childhood: a systematic review with meta-analysis of prospective studies. J Pediatr 2001;139:261-6.

21 Hook B, Kiwi R, Amini SB, et al. Neonatal morbidity after elective repeat cesarean section and trial of labor. Pediatrics 1997; 100:348-53.

22 Xu B, Pekkanen J, Hartikainen AL, et al. Caesarean section and risk of asthma and allergy in adulthood. J Allergy Clin Immunol $2001 ; 107: 732-3$

\section{Call for papers}

10th European Forum on Quality Improvement in Health Care

13-15 April 2005, ExCel, Docklands, London

For further information on how to submit your paper please go to:

http://www.quality.bmipg.com 